\title{
Gestão do conflito escolar: da classificação dos conflitos aos modelos de mediação
}

\author{
Álvaro Chrispino
}

\section{Resumo}

presente trabalho se inicia apresentando um recente estudo realizado por um instituto de pesquisa onde fica patente a importância que o jovem atribui à educação, à escola e ao professor, ao mesmo tempo em que apresenta sua preocupação com a violência. Com este motivador, discute os conceitos de conflito e de conflito escolar, apresenta inúmeras maneiras de classificar os conflitos e os conflitos escolares a fim de contribuir com o entendimento do problema, indica a mediação de conflito como alternativa potente e viável para a diminuição da violência escolar e, ao final, enumera questões que devem ser consideradas quando a escola se propõe a implantar um programa de mediação escolar do conflito.

Palavras-chave: Políticas educacionais. Violência escolar. Conflito escolar. Mediação do conflito escolar.

\section{Abstract \\ School-Based Conflict Management: from the classification of conflicts to models of mediation}

The enclosed article starts by presenting a recent study carried out by a research institute and it demonstrates the importance that the student gives to education, to school, to the teacher and at the same time it shows his concern with violence. With such motivation, it discusses the concepts of conflicts and school conflicts in order to contribute to the clarification of the problem, it

indicates the mediation of the conflict as a powerful and potent alternative to reduce school violence.

Finally, it lists questions that should be taken into account when the school has in mind the implementation of its program of mediation conflict.

Keywords: Educational policies. School violence. School conflict. Mediation of school conflict.

\section{Resumen}

Gestión del conflicto escolar: de la clasificación de los conflictos a los medelos de mediación

El artículo presenta un reciente estudio 
realizado por un instituto de pesquisa que muestra la importancia que el joven atribuye a la educación, a la escuela y al profesor y, también, su preocupación con la violencia. El texto aborda los conceptos de conflicto y de conflicto escolar, presenta innumeras maneras de clasificar los conflictos y los conflictos escolares a fin de contribuir para el entendimiento del problema e indica la mediación del conflicto como alternativa potente y viable para la disminución de la violencia escolar. Al final enumera cuestiones que deben ser consideradas cuando la escuela se propone a implantar un programa de mediación escolar del conflicto.

Palavras clave: Políticas educacionales. Violencia escolar. Conflicto escolar. Mediación del conflicto escolar.

\section{Introdução}

A seqüência de episódios violentos envolvendo o espaço escolar não deixa dúvida quanto à necessidade de se trazer este tema à grande arena de debates da educação brasileira. Os acontecimentos que se repetem nos diversos pontos do país, e que nos privaremos de citar por ser absolutamente desnecessário para a análise, expõem uma dificuldade brasileira pela qual já passaram outros países, o que seria, por si só, um convite para a reflexão de educadores e de gestores políticos, visto que o movimento mundial em educação indica semelhança de acontecimentos mesmo que em momentos diferentes da linha de tempo.

Já dissemos alhures (CHRISPINO; CHRISPINO, 2002) que os problemas novos da violência escolar no Brasil são um problema antigo em outros países como Estados Unidos, França, Reino Unido, Espa- nha, Argentina e Chile, dentre outros, onde já se percebe um conjunto de políticas públicas mais ou menos eficientes dirigidas aos diversos atores que compõem este complexo sistema que é o fenômeno violência escolar. Estes países possuem já alguma tradição em programa de redução da violência escolar como apontam Debarbieux e Blaya (2002) e, no Brasil, é possível enumerar alguns estudos pontuais até aproximadamente 2000, quando passamos a contar com um número maior de estudos e pesquisas sobre os diversos ângulos da violência escolar como, por exemplo, Abramovay e Rua (2002), Ortega e Del Rey (2002), Chrispino e Chrispino (2002), dentre outros.

Os diversos estudos publicados em língua portuguesa disseminaram idéias, aclararam os problemas e listaram alternativas já testadas em sociedades distintas, permitindo que a comunidade educacional brasileira reunisse informações para enfrentar um problema importante, no esforço de tirar a "diferença" causada por alguns anos de atraso na percepção do problema e na busca de soluções próprias. No rastro dessas iniciativas, a produção acadêmica brasileira já começa a demonstrar bons resultados no tema, apesar de serem encontrados apenas 7 grupos de pesquisa no Diretório LATTES, quando consultado utilizando as palavras chave "violência escolar" e "violência na escola", o que indica que a produção deve estar vinculada a grupos com linhas de pesquisa e temas de pesquisa outros que absorvem os assuntos correlacionados com o universo da violência escolar.

Experiências importantes vêm sendo realizadas como a do programa de Mestrado da Universidade Católica de Brasília/ Observatório da Violência que já produz 
uma série de pesquisas focada na violência escolar, mas correlacionando-a com a visão docente (OLIVEIRA, M. G. P., 2003; OLIVEIRA, R. B. L., 2004), com a comunidade (SILVA, 2004), com o rendimento escolar (VALE, 2004), com a gestão escolar (CARREIRA, 2005), com a visão discente (RIBEIRO, 2004; FERNANDES, 2006), dentre outras.

Tudo leva a crer que o tema tenha ocupado um lugar de destaque na sociedade e academia brasileiras, o que pode resultar na transferência da escola da editoria policial para a editoria de direitos sociais nos grandes veículos de mídia nacional.

\section{Educação, juventude e violência}

A formação de opinião sobre a escola e a juventude exclusivamente pelas manchetes de jornais e televisão, resulta numa visão por ângulos restritos da realidade educacional.

A educação - apesar da existência de programas importantes como o Fundo de Manutenção e Desenvolvimento do Ensino Fundamental e de Valorização do Magistério - FUNDEF-, vem sofrendo com a falta de políticas públicas de longo prazo e efetivas que atendam às necessidades da comunidade, vem sendo esvaziada pelo afastamento de bons docentes por conta do desprestígio e da perda significativa de salários, vem sendo "sucateada" pela ineficácia dos sistemas de gestão e por recursos cada vez mais reduzidos, vem se tornando cada vez mais "profanada" quando a história nos ensinou sobre uma escola cercada de respeito, pertencimento e "sacralidade".
No que pese tudo isto, recentemente o Sindicato dos Estabelecimentos de Ensino do Rio de Janeiro - Sinepe Rio -, solicitou ao IBOPE uma pesquisa intitulada "O jovem, a sociedade e a ética" (RIO DE JANEIRO, 2006), que recolheu opiniões de jovens entre 14 e 18 anos. $O$ resultado mostra o quanto a escola e a educação povoam o imaginário dos jovens, o quanto estes ainda vêem na escola e na educação instrumentos importantes para suas vidas e o quanto a violência na escola os afasta de seus sonhos ou os amedronta. Vejamos alguns resultados:

Pergunta: Dentre estes, quais são os dois mais graves problemas do Brasil?

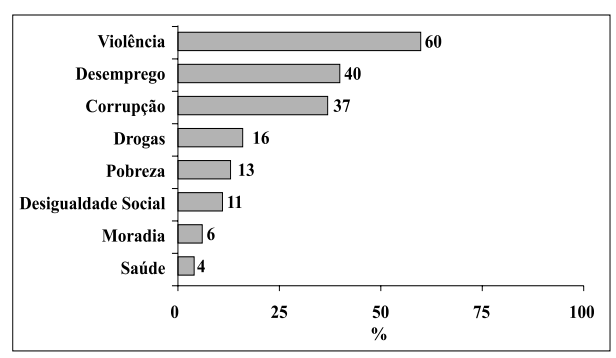

Pergunta: Quem você considera mais responsável pela garantia de um bom futuro para pessoas como você?

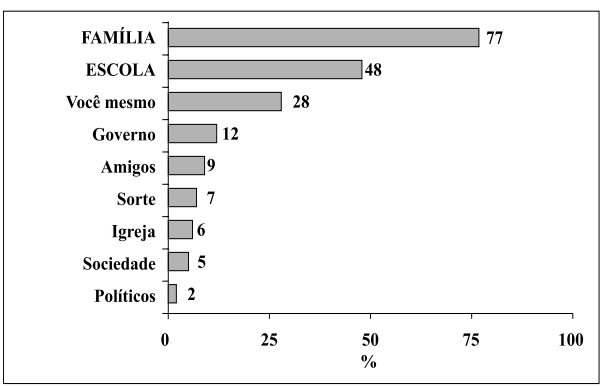


Pergunta: Gostaria que você dissesse, para cada uma das pessoas e instituições que vou falar, se você confia ou não confia

\begin{tabular}{|l|c|c|c|}
\hline INSTITUIÇÕES & CONFIA & NÃO CONFIA & NÃO TEM OPINIÃO \\
\hline Professores & $84 \%$ & $13 \%$ & $3 \%$ \\
\hline Escola Particular & $77 \%$ & $18 \%$ & $5 \%$ \\
\hline Escola Pública & $76 \%$ & $19 \%$ & $5 \%$ \\
\hline Médicos & $75 \%$ & $21 \%$ & $4 \%$ \\
\hline Religião & $71 \%$ & $23 \%$ & $6 \%$ \\
\hline Igreja Católica & $66 \%$ & $26 \%$ & $8 \%$ \\
\hline Igreja Evangélica & $61 \%$ & $30 \%$ & $8 \%$ \\
\hline Televisão & $60 \%$ & $36 \%$ & $4 \%$ \\
\hline Rádios & $62 \%$ & $35 \%$ & $4 \%$ \\
\hline Jornais & $59 \%$ & $37 \%$ & $4 \%$ \\
\hline
\end{tabular}

Pergunta: Para cada frase citada, gostaria de saber se você concorda ou discorda

\begin{tabular}{|l|c|c|}
\hline PONTOS & CONCORDA & DISCORDA \\
\hline A educação dos jovens deve ter limites bem definidos & $82 \%$ & $14 \%$ \\
\hline $\begin{array}{l}\text { No Brasil, é possível melhorar a } \\
\text { condição social através do voto }\end{array}$ & $73 \%$ & $21 \%$ \\
\hline $\begin{array}{l}\text { No Estado, um cidadão não tem só direitos, } \\
\text { tem deveres para com a sociedade }\end{array}$ & $70 \%$ & $24 \%$ \\
\hline O voto pode mudar a situação do país & $64 \%$ & $30 \%$ \\
\hline $\begin{array}{l}\text { O importante para os jovens é viver o momento, } \\
\text { sem se preocupar com o futuro }\end{array}$ & $57 \%$ & $40 \%$ \\
\hline Os jovens são desmotivados e nada lhes interessa & $50 \%$ & $46 \%$ \\
\hline $\begin{array}{l}\text { A experiência profissional é mais } \\
\text { importante que a educação }\end{array}$ & $49 \%$ & $44 \%$ \\
\hline $\begin{array}{l}\text { Os direitos humanos no Brasil só protegem os que } \\
\text { não respeitam os direitos dos outros }\end{array}$ & $49 \%$ & \\
\hline
\end{tabular}


Pergunta: Dentre estes, para qual ponto você julga que uma boa escola deveria estar voltada? $\left(1^{\circ}\right.$ e $2^{\circ}$ lugares $)$

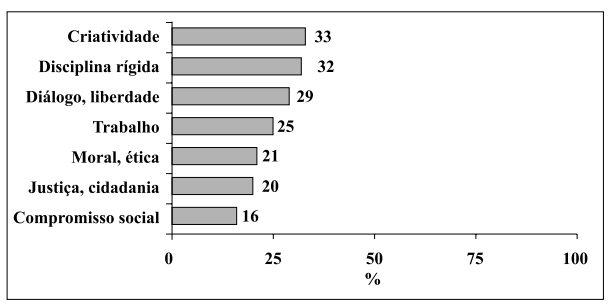

Podemos depreender da pesquisa (1) que o jovem identifica na violência o maior problema da sociedade atual, superando, inclusive, o desemprego; (2) que a escola ocupa o segundo lugar entre as instituições importantes para o desenho de seu futuro, perdendo apenas para a família; (3) professores e escolas são as duas "instituições" que encabeçam a lista de confiança com altos índices percentuais; (4) os jovens, diferentemente do que diz o senso comum, solicitam os limites próprios à juventude e (5) confirmando o item 4, o jovem julga que a disciplina rígida, juntamente com criatividade e diálogo, fazem parte da boa escola, para desespero de gestores e docentes que defendem o "vai-levando" ou o laissez-faire, certamente pela lei de menor esforço, já que o salário é o mesmo no final do mês.

Apesar de todas as dificuldades, o jovem ainda crê na educação como alternativa e na escola como instrumento de mobilidade social e de diferenciação para o futuro.

Motivado por isso, podemos buscar entender melhor o que pode estar causando a violência na escola, sempre lembrando que a nossa é uma leitura, uma proposta, uma alternativa. Certamente haverá outras, desenvolvidas e amparadas a partir de outras percepções e experiências.

\section{O conflito e o conflito na escola}

Conflito é toda opinião divergente ou maneira diferente de ver ou interpretar algum acontecimento. A partir disso, todos os que vivemos em sociedade temos a experiência do conflito. Desde os conflitos próprios da infância, passamos pelos conflitos pessoais da adolescência e, hoje, visitados pela maturidade, continuamos a conviver com o conflito intrapessoal (ir/não ir, fazer/não fazer, falar/não falar, comprar/não comprar, vender/não vender, casar/não casar etc.) ou interpessoal, sobre o qual nos deteremos. São exemplos de conflito interpessoal a briga de vizinhos, a separação familiar, a guerra e o desentendimento entre alunos. (CHRISPINO; CHRISPINO, 2002).

Poderemos buscar, numa adaptação de Redorta (2004, p. 33), grandes exemplos de conflito nos conhecidos movimentos de rompimento de paradigmas:

\begin{tabular}{|l|l|l|l|}
\hline AUTOR & TIPO DE CONFLITO & PROCESSO RESULTANTE & SíNTESE \\
\hline Freud & Conflito entre o desejo e a proibição & Repressão e defesa & Luta pelo dever \\
\hline Darwin & Conflito entre o sujeito e o meio & Diferenciação e adaptação & Luta por existir \\
\hline Marx & Conflito entre classes sociais & $\begin{array}{l}\text { Estratificação social } \\
\text { hierarquia }\end{array}$ & Luta pela igualdade \\
\hline Piaget & Conflito nas decisões e experiências & $\begin{array}{l}\text { Aprendizagem } \\
\text { Resolução de problemas }\end{array}$ & Luta por ser \\
\hline
\end{tabular}


O conflito, pois, é parte integrante da vida e da atividade social, quer contemporânea, quer antiga. Ainda no esforço de entendimento do conceito, podemos dizer que o conflito se origina da diferença de interesses, de desejos e de aspirações. Percebe-se que não existe aqui a noção estrita de erro e de acerto, mas de posições que são defendidas frente a outras, diferentes.

Um exemplo claro da dificuldade que temos para lidar com o conflito é a nossa incapacidade de identificar as circunstâncias que derivam do conflito ou redundam nele. Em geral, nas escolas e na vida, só percebemos o conflito quando este produz suas manifestações violentas. Daí podemos tirar, pelo menos, duas conclusões: a primeira é que se ele se manifestou de forma violenta é porque já existia antes na forma de divergência ou antagonismo, e nós não soubemos ou não fomos preparados para identificá-lo; a segunda é que toda a vez que o conflito se manifesta, nós agimos para resolvêlo, coibindo a manifestação violenta. $E$ neste caso, esquecemos que problemas mal resolvidos se repetem! (CHRISPINO; CHRISPINO, 2002)

Ao definirmos conflito como o resultado da diferença de opinião ou interesse de pelos menos duas pessoas ou conjunto de pessoas, devemos esperar que, no universo da escola, a divergência de opinião entre alunos e professores, entre alunos e entre os professores seja uma causa objetiva de conflitos. Uma segunda causa de conflitos é a dificuldade de comunicação, de assertividade das pessoas, de condições para estabelecer o diálogo.

Temos defendido que a massificação da educação se, por um lado, garantiu o acesso dos alunos à escola, por outro, expôs a escola a um contingente de alunos cujo perfil ela - a escola - não estava preparada para absorver.

Antes, em passado remoto, a escola era procurada por um tipo padrão de aluno, com expectativas padrões, com passados semelhantes, com sonhos e limites aproximados. Os grupos eram formados por estudantes de perfis muito próximos. Com a massificação, trouxemos para o mesmo espaço alunos com diferentes vivências, com diferentes expectativas, com diferentes sonhos, com diferentes valores, com diferentes culturas e com diferentes hábitos [...], mas a escola permaneceu a mesma! Parece óbvio que este conjunto de diferenças é causador de conflitos que, quando não trabalhados, provocam uma manifestação violenta. Eis, na nossa avaliação, a causa primordial da violência escolar.

A fim de exemplificar a tese que defendemos, podemos lançar mão da pesquisa de Fernandes (2006, p. 103) realizada com alunos e professores de diferentes escolas do Distrito Federal. Ao solicitar que professores e alunos identifiquem níveis de gravidade de violência a partir de ocorrências cotidianas, percebe-se a divergência de opinião: isto dá origem a conflitos. Vejamos alguns exemplos: 


\begin{tabular}{|l|c|c|c|c|}
\hline ATITUDES & \multicolumn{2}{|c|}{ ESCOLA 1-PÚBLICA } & \multicolumn{2}{c|}{ ESCOLA 2-PRIVADA } \\
\hline OPINIÃO & DISCENTE & DOCENTE & DISCENTE & DOCENTE \\
\hline Aluno bate em colega menor & 47,4 (média) & 64,6 (alta) & 51,6 (alta) & 61,2 (alta) \\
\hline Briga entre alunos & 38,1 (média) & 60,5 (alta) & 52,9 (alta) & 55,8 (alta) \\
\hline Toque de mão no colega com sentido sexual & 32,0 (média) & 60,5 (alta) & 27,2 (baixa) & 54,9 (alta) \\
\hline Insulto de aluno a aluno & 32,0 (média) & 56,5 (alta) & 31,8 (média) & 54,9 (alta) \\
\hline
\end{tabular}

Consideram-se altas as taxas entre 68 a 48 , médias as taxas entre 47 a 31 e baixas as taxas menores que 30 .

Podemos esperar que, pela diferença entre as opiniões, haja conflito no espaço escolar. Um conflito criado pela diferença de conceito ou pelo valor diferente que se dá ao mesmo ato. Professores e alunos dão valores diferentes à mesma ação e reagem diferentemente ao mesmo ato: isso é conflito. Como a escola está acostumada historicamente a lidar com um tipo padrão de aluno, ela apresenta a regra e requer dos alunos enquadramento automático. Quanto mais diversificado for o perfil dos alunos (e dos professores), maior será a possibilidade de conflito ou de diferença de opinião. $E$ isso numa comunidade que está treinada para inibir o conflito, pois este é visto como algo ruim, uma anomalia do controle social.

Porém, o mito de que o conflito é ruim está ruindo. $\bigcirc$ conflito começa a ser visto como uma manifestação mais natural e, por conseguinte, necessária às relações entre pessoas, grupos sociais, organismos políticos e Estados. $O$ conflito é inevitável e não se devem suprimir seus motivos, até porque ele possui inúmeras vantagens dificilmente percebidas por aqueles que vêem nele algo a ser evitado:

- Ajuda a regular as relações sociais;

- ensina a ver o mundo pela perspectiva do outro;

- permite o reconhecimento das diferenças, que não são ameaça, mas resultado natural de uma situação em que há recursos escassos;
- ajuda a definir as identidades das partes que defendem suas posições;

- permite perceber que o outro possui uma percepção diferente;

- racionaliza as estratégias de competência e de cooperação;

- ensina que a controvérsia é uma oportunidade de crescimento e de amadurecimento social.

Outro mito importante construído em torno do conflito, e que está também sendo superado, é aquele que diz que o mesmo atenta contra a ordem. Na verdade, o conflito é a manifestação da ordem em que ele próprio se produz e da qual se derivam suas conseqüências principais. $\bigcirc$ conflito é a manifestação da ordem democrática, que o garante e o sustenta.

A ordem e o conflito são resultado da interação entre os seres humanos. A ordem, em toda sociedade humana, não é outra coisa senão uma normatização do conflito. Tomemos como exemplo o conflito político: apesar de parecer ruptura da ordem anterior, há continuidade e regularidade em alguns aspectos tidos como indispensável pela sociedade, que exige a ordem e de onde emanam os conflitos.

Somente estudo e compreensão das relações que existem dentro da ordem podem permitir o entendimento completo dos conflitos que nela se originam e que, por fim, são a razão 
de sua existência. Por exemplo, os sócios que brigam. É necessário ver as condições em que se fez a sociedade e as expectativas dos sócios. Possivelmente, cada um deles terá entendimento pessoal das regras que iniciaram a sociedade e possuíam, por derivação, expectativas diferentes. Instala-se o conflito!

O conflito está regulado de tal modo que nem sempre nos damos conta sequer de sua existência. Como exemplo disso, temos o futebol ou o desfile das escolas de samba: eles excluem a violência como a entendemos comumente e prevêem um modelo de comportamento cooperativo, mas os interesses são frontalmente conflitantes!

Acontece, muitas vezes, que o conflito é deflagrado e não sabemos exatamente o que o provoca, pois a posição conflitante é diferente do interesse real das partes. $\bigcirc$ interesse é a motivação objetiva/subjetiva de uma conduta, a partir da qual esta se estrutura e se distingue da posição, que é a forma exterior do conflito, que pode esconder o real interesse envolvido. Os comerciantes têm interesses conflitantes: o vendedor quer vender mais caro, enquanto o comprador quer pagar menos [...], mas os interesses são claros e definidos. Diferentemente com o que ocorre no conflito causado pela separação de casais que brigam pela posse da casa onde moravam, mesmo possuindo outras imóveis de igual valor. $\mathrm{Na}$ verdade, a posição de posse da casa esconde um interesse implícito: quem ficar com a casa do casal tem a sensação de vitória sobre o outro.

\section{Classificações dos conflitos}

A fim de melhor entender suas possibilidades, buscaremos alguns exemplos de classificação de conflito, pois, segundo Redorta (2004, p. 95),

classificar é uma forma de dar sentido.

A classificação costuma ser hierárquica e permite estabelecer relações de pertencimento. Ao classificar definimos, e ao defini-lo, tomamos uma decisão a respeito da essência de algo.

Vamos buscar algumas classificações gerais de conflito segundo Moore (1998), Deutsch (apud MARTINEZ ZAMPA, 2004) e Redorta (2004) e classificações de conflitos escolares a partir de Martinez Zampa (2004) e Nebot (2000).

Para Moore (1998, p. 62), os conflitos podem ser classificados em estruturais, de valor, de relacionamento de interesse e quanto aos dados:

\begin{tabular}{|l|l|}
\hline TIPOS DE CONFLITO & CAUSAS DOS CONFLITOS \\
\hline Estruturais & $\begin{array}{l}\text { Padrões destrutivos de comportamento ou interação; controle, } \\
\text { posse ou distribuição desigual de recursos; poder e autoridade } \\
\text { desiguais; fatores geográficos, físicos ou ambientais que impeçam } \\
\text { a cooperação; pressões de tempo. }\end{array}$ \\
\hline De valor & $\begin{array}{l}\text { Critérios diferentes para avaliar idéias ou comportamentos; } \\
\text { objetivos exclusivos intrinsecamente valiosos; modos de vida, } \\
\text { ideologia ou religião diferente. }\end{array}$ \\
\hline De relacionamento & $\begin{array}{l}\text { Emoções fortes; percepções equivocadas ou estereótipos; comunicação } \\
\text { inadequada ou deficiente; comportamento negativo - repetitivo. }\end{array}$ \\
\hline De interesse & $\begin{array}{l}\text { Competição percebida ou real sobre interesses fundamentais } \\
\text { (conteúdo); interesses quanto a procedimentos; interesses psicológicos. }\end{array}$ \\
\hline Quanto aos dados & $\begin{array}{l}\text { Falta de informação; informação errada; pontos de vista diferentes } \\
\text { sobre o que é importante; interpretações diferentes dos dados; } \\
\text { procedimentos de avaliação diferentes. }\end{array}$ \\
\hline
\end{tabular}


Para Deutsch (apud MARTINEZ ZAMPA, 2004, p. 27), os conflitos podem ser classificados em 6 tipos: Verídicos (conflitos que existem objetivamente), contingentes (situações que dependem de circunstâncias que mudam facilmente), descentralizados (conflitos que ocorrem fora do conflito central), mal atribuídos (se apresentam entre partes que não mantêm contatos entre si), latentes (conflitos cuja origem não se exteriorizam) e falsos (se baseiam em má interpretação ou percepção equivocada).

Para Redorta (2004), a tipologia de conflito é de tal importância que ele dedica toda uma obra a essa tarefa. Podemos sintetizar a sua tipologia, no quadro a seguir:

\begin{tabular}{|l|l|}
\hline TIPOS DE CONFLITOS... & O CONFLITO OCORRE QUANDO \\
\hline De recursos escassos & Disputamos por algo que não existe suficientemente para todos. \\
\hline De poder & Disputamos porque algum de nós quer mandar, dirigir ou controlar o outro. \\
\hline De auto-estima & Disputamos porque meu orgulho pessoal se sente ferido. \\
\hline De valores & Disputamos porque meus valores ou crenças fundamentais estão em jogo. \\
\hline De estrutura & $\begin{array}{l}\text { Disputamos por um problema cuja solução requer longo prazo, } \\
\text { esforços importantes de muitos, e meios estão além de } \\
\text { minha possibilidade pessoal. }\end{array}$ \\
\hline De identidade & Disputamos porque o problema afeta minha maneira intima de ser o que sou. \\
\hline De norma & Disputamos porque meus valores ou crenças fundamentais estão em jogo. \\
\hline De expectativas & Disputamos porque não se cumpriv ou se fraudou o que um esperava do outro. \\
\hline De inadaptação & Disputamos porque modificar as coisas produz uma tensão que não desejo. \\
\hline De informação & $\begin{array}{l}\text { Disputamos por algo que se disse ou não se disse } \\
\text { ou que se entendeu de forma errada. }\end{array}$ \\
\hline De interesses & Disputamos porque meus interesses ou desejos são contrários aos do outro. \\
\hline De atribuição & $\begin{array}{l}\text { Disputamos porque o outro não assume a sua culpa } \\
\text { ou responsabilidade em determinada situação. }\end{array}$ \\
\hline De relações pessoais & Disputamos porque habitualmente não nos entendemos como pessoas. \\
\hline De inibição & Disputamos porque claramente a solução do problema depende do outro. \\
\hline De legitimação & $\begin{array}{l}\text { Disputamos porque o outro não está de alguma maneira autorizado } \\
\text { a atuar como o faz, ou tem feito ou pretende fazer. }\end{array}$ \\
\hline
\end{tabular}

É possível, ainda, identificar conflitos escolares ou mesmo educacionais a partir de Martinez Zampa (2005) e de Nebot (2000). Certamente, a característica da escola ou do sistema educacional favorecem este tipo de categorização, por se restringirem a um universo conhecido, com atores permanentes (alunos, profes- sores, técnicos e comunidade) e com rotinas estabelecidas (temática, horários, espaços físicos etc). A maneira de lidar com o conflito escolar ou educacional é que irá variar de uma escola que veja o conflito como instrumento de crescimento ou que o interpreta como um grave problema que deva ser abafado. 
Na comunidade escolar existem pontos que contribuem para o surgimento dos conflitos e que, no mais das vezes, não são explícitos ou mesmo percebidos. A prioridade que se dá para os diferentes conflitos escolares é um primeiro ponto. Martinez Zampa (2005, p. 29) diz que os professores consideram que os conflitos mais freqüentes e importantes se dão entre seus colegas e diretores, colocando em segundo lugar de importância os conflitos entre alunos. Essa posição não é ratificada por Oliveira e Gomes (2004, p. 52-53), que descrevem como os docentes vêem os valores e violência escolares. Ao se referirem às escolas que foram pesquisadas, escrevem:

Clima entre direção, professores e alunos parecia bastante amistoso. No entanto, a Associação de Pais e Mestres e o Conselho Escolar funcionavam precariamente devido à falta de participação e envolvimento da comunidade escolar.

relacionamento entre os professores parecia muito bom, manifestado, inclusive, pelos intervalos muito animados. Segundo informações colhidas, a amizade entre os docentes continuava fora dos muros da escola, nas festas de confraternizações, aniversários, churrascos e outras.

A leitura externa da comunidade (cidadãos e pais) pode achar que professores e diretores - profissionais e adultos que são -, devam lidar profissionalmente com as possíveis dificuldades que surjam no exercício da atividade docente e que os conflitos entre alunos, e destes com seus professores, é que efetivamente merecem ser vistos como prioridade.
Como conflitos educacionais ou entre membros da comunidade educacional, Martinez Zampa (2005, p. 30-31) enumera 4 tipos diferentes:

- Conflito em torno da pluralidade de pertencimento: surge quando o docente faz parte de diferentes estabelecimentos de ensino ou mesmo de níveis diferentes de ensino.

- Conflitos para definir o projeto institucional: surge porque a construção do projeto educacional favorece a manifestação de diferentes posições quanto a objetivos, procedimentos e exigências no estabelecimento escolar.

- Conflito para operacionalizar o projeto educativo: surge porque, no momento de executar o projeto institucional, surgem divergências nos âmbitos de planejamento, execução e avaliação, levando a direção a lançar mão de processos de coalizão, adesões, etc.

- Conflito entre as autoridades formal e funcional: surge quando não há coincidência entre a figura da autoridade formal (diretor) e da autoridade funcional (líder situacional)

Os conflitos educacionais, para efeito de estudo, são aqueles provenientes de ações próprias dos sistemas escolares ou oriundos das relações que envolvem os atores da comunidade educacional mais ampla. Certamente poderíamos ainda apontar os que derivam dos exercícios de poder, dos que se originam das diferenças pessoais, dos que resultam de intolerâncias de toda ordem, os que possuem fundo político ou ideológico, o que fugiria do foco principal deste trabalho, voltado pela a escola e seu entorno. Saindo do universo geral dos conflitos educacionais - enumerados restritamente - podemos relacionar os que 
chamaremos de conflitos escolares, por acontecerem no espaço próprio da escola lou com seus atores diretos.

Dentre as classificações possíveis, escolhemos adaptar a de Martinez Zampa (2005, p. 31-32) para ilustrar o texto. Os conflitos que ocorrem com maior freqüência se dão:

- Entre docentes, por:

- falta de comunicação;

- interesses pessoais;

- questões de poder;

- conflitos anteriores;

- valores diferentes;

- busca de "pontuação" (posição de destaque);

- conceito anual entre docentes;

- não-indicação para cargos de ascensão hierárquica;

- divergência em posições políticas ou ideológicas.

- Entre alunos e docentes, por:

- não entender o que explicam;

- notas arbitrárias;

- divergência sobre critério de avaliação;

- avaliação inadequada (na visão do aluno);

- descriminação;

- falta de material didático;

- não serem ouvidos (tanto alunos quanto docentes);

- desinteresse pela matéria de estudo.

- Entre alunos, por:

- mal entendidos;

- brigas;

- rivalidade entre grupos;

- descriminação;

- bullying;

- uso de espaços e bens;

- namoro;

- assédio sexual;

- perda ou dano de bens escolares;
- eleições (de variadas espécies);

- viagens e festas.

- Entre pais, docentes e gestores, por:

- agressões ocorridas entre alunos e entre os professores;

- perda de material de trabalho;

- associação de pais e amigos;

- cantina escolar ou similar;

- falta ao serviço pelos professores;

- falta de assistência pedagógica pelos professores;

- critérios de avaliação, aprovação e reprovação;

- uso de uniforme escolar;

- não-atendimento a requisitos "burocráticos" e administrativos da gestão.

Segundo Nebot (2000, p. 81-82), os conflitos escolares podem ser categorizados em organizacionais, culturais, pedagógicos e de atores. A seguir, detalhamos cada um dos tipos:

- Organizacionais

1. setoriais: são aqueles se produzem a partir da divisão de trabalho e do desenho hierárquico da instituição, que gera a rotina de tarefas e de funções (direção, técnicoadministrativos, professores, alunos, etc);

2. o salário e as formas como o dinheiro se distribui no coletivo, afetando a qualidade de vida dos funcionários e docentes, etc

3. se são públicas ou privadas.

- Culturais

1. comunitários: são aqueles que emanam de redes sociais de diferentes atores onde está situada a escola. Rompem-se as concepções rígidas dos muros da escola, am- 
pliando-se as fronteiras (por exemplo, os bairros e suas características, as organizações sociais do bairro, as condições econômicas de seus habitantes, etc)

2. raciais e identidades: são aqueles grupos sociais que possuem um pertencimento e afiliação que faz a sua condição de existência no mundo. Estes, com suas características culturais, folclóricas, ritualísticas, patrocinam uma série de práticas e habitus que retroalimentam o estabelecimento de ensino (por exemplo, a presença de fortes componentes migratórios na região, etc)

- Pedagógicos

São aqueles que derivam do desenho estratégico da formação e dos dispositivos de controle de qualidade e das formas de ensinar, seus ajustes ao currículo acadêmico e suas formas de produção (por exemplo, não é a mesma coisa ensinar matemática que literatura, e ambas possuem procedimentos similares, mas diferentes; a organização dos horários de das turmas e dos professores; as avaliações, etc)

- Atores

São aqueles que denominamos "pessoas" e que devem ser distinguidos:

1. em grupos e subgrupos, que ocorrem em qualquer âmbito (turma, corpo docente, direção etc)

2. familiares, donde derivam as ações que caracterizam a dinâmica familiar que afeta diretamente a pessoa, podendo produzir o fenômeno de afastamento familiar que acarreta o "depósito" do aluno na escola.
3. individuais, que são aqueles onde a "patologia" toma um membro da organização escolar. Neste caso, há sempre o risco da estigmatização do membro da comunidade que é o causador do conflito.

No momento em que realçamos o conflito na escola, gostaríamos de chamar à atenção a capacidade da escola em perceber a existência do conflito e a sua capacidade de reagir positivamente a ele, transformando-o em ferramenta do que chamamos de tecnologia social, uma vez que o aprendizado de convivência e gestão do conflito são para sempre.

\section{Por que a mediação do conflito na escola}

Façamos um retrospecto do que foi apresentado até aqui a fim de melhor encaminhar os pontos seguintes.

Até aqui apresentamos as expectativas dos estudantes com a ascensão social por meio da educação, sua confiança nos professores e na escola, suas dificuldades por conta da violência que lança seus tentáculos nas escolas e discutimos o conflito em geral e na escola, em particular. Apresentamos a tese onde o conflito surge da diferença de opiniões e divergência de interpretações. Logo, se a escola é o universo que reúne alunos diferentes, ela é o palco onde certamente o conflito se instalará. E, se o conflito é inevitável, devemos aprender o ofício da mediação de conflito para que esta técnica se aprimore facultando a cultura da mediação de conflito.

Chamaremos de mediação de conflito o procedimento no qual os participantes, 
com a assistência de uma pessoa imparcial - o mediador -, colocam as questões em disputa com o objetivo de desenvolver opções, considerar alternativas e chegar a um acordo que seja mutuamente aceitável.

A mediação pode induzir a uma reorientação das relações sociais, a novas formas de cooperação, de confiança e de solidariedade; formas mais maduras, espontâneas e livres de resolver as diferenças pessoais ou grupais.

A mediação induz atitudes de tolerância, responsabilidade e iniciativa individual que podem contribuir para uma nova ordem social.

primeiro ponto para a introdução da mediação de conflito no universo escolar é assumir que existem conflitos e que estes devem ser superados a fim de que a escola cumpra melhor as suas reais finalidades. Há, portanto, dois tipos de escola: aquela que assume a existência de conflito e o transforma em oportunidade e aquela que nega a existência do conflito e, com toda a certeza, terá que lidar com a manifestação violenta do conflito, que é a tão conhecida violência escolar.

As escolas que valorizam o conflito e aprendem a trabalhar com essa realidade, são aquelas onde o diálogo é permanente, objetivando ouvir as diferenças para meIhor decidirem; são aquelas onde o exercício da explicitação do pensamento é incentivado, objetivando o aprendizado da exposição madura das idéias por meio da assertividade e da comunicação eficaz; onde o currículo considera as oportunidades para discutir soluções alternativas para os diversos exemplos de conflito no campo das idéi- as, das ideologias, do poder, da posse, das diferenças de toda ordem; onde as regras e aquilo que é exigido do aluno nunca estão no campo do subjetivo ou do entendimento tácito: estão explícitos, falados e discutidos. Em síntese, devemos ser explícitos naquilo que esperamos dos estudantes e naquilo que nos propomos a fazer.

Sobre a gestão destes itens, escreve Heredia, citando Ray Scanhaltz (apud HEREDIA, 1998), diretor de programas educacionais de San Francisco:

Pedir aos estudantes disciplina, sem provê-los das habilidades requeridas, é como pedir a um transeunte que encontre Topeka, Kansas, sem fazer uso de uma bússola [...]. Não podemos esperar que os estudantes se comportem de um modo disciplinado se não possuem as habilidades para fazê-lo.

É possível, também pensar na introdução do tema mediação de conflito no currículo escolar, o que seria uma oportunidade para verbalizar a questão e tornar claro o que se espera dele - o jovem - no conjunto de comportamentos sociais. De outra forma, é dizer ao jovem e à criança que suas diferenças podem transformar-se em antagonismos e que, se estes não forem entendidos, evolvem para o conflito, que deságua na violência. Cabe ressaltar que esse aprendizado e essa percepção social, quando ocorrem com o estudante, são para sempre.

Eis algumas vantagens identificadas para a mediação do conflito escolar (CHRISPINO, 2004):

- O conflito faz parte de nossa vida pessoal e está presente nas instituições. 'É melhor enfrentá-lo com habilidade 
pessoal do que evitá-lo' (HEREDIA, 1998 apud CHRISPINO, 2004).

- Apresenta uma visão positiva do conflito, rompendo com a imagem histórica de que ele é sempre negativo.

- Constrói um sentimento mais forte de cooperação e fraternidade na escola.

- Cria sistemas mais organizados para enfrentar o problema divergência $\rightarrow$ antagonismo $\rightarrow$ conflito $\rightarrow$ violência.

- $\bigcirc$ uso de técnicas de mediação de conflitos pode melhorar a qualidade das relações entre os atores escolares e melhorar o "clima escolar".

- O uso da mediação de conflitos terá conseqüências nos índices de violência contra pessoas, vandalismo, violência contra o patrimônio, incivilidades, etc.

- Melhora as relações entre alunos, facultando melhores condições para o bom desenvolvimento da aula.
- Desenvolve o autoconhecimento e o pensamento crítico, uma vez que o aluno é chamado a fazer parte da solução do conflito.

- Consolida a boa convivência entre diferentes e divergentes, permitindo o surgimento e o exercício da tolerância.

- Permite que a vivência da tolerância seja um patrimônio individual que se manifestará em outros momentos da vida social.

Cremos que as vantagens dos programas de mediação escolar são bastante numerosas. Apesar disso, poucas são as avaliações quantitativas sobre o impacto dos programas de mediação de conflito. Kmitta (1999, p. 293) ensaia um estudo de resultados quantitativos a partir de dez programas de mediação escolar nos Estados Unidos, que podem indicar alguns resultados promissores nesse tipo de técnica e nesse esforço de implantação da cultura de mediação de conflito. Aponta ele:

\section{Resumo de estudos que documentam mediações e porcentagens de êxito}

\begin{tabular}{|l|l|l|l|l|}
\hline NOME & $\begin{array}{c}\text { ANO DO } \\
\text { ESTUDO }\end{array}$ & ESTADO & $\begin{array}{c}\text { No DE } \\
\text { MEDIAÇÕES }\end{array}$ & $\begin{array}{c}\hat{E} X I T O \\
(\%)\end{array}$ \\
\hline $\begin{array}{l}\text { The Ohio Commission on } \\
\text { Dispute Resolution }\end{array}$ & $1990 / 93$ & Ohio & 256 & $100 \%$ \\
\hline Model School & $1993 / 94$ & Georgia & 126 & $96,8 \%$ \\
\hline Jones e Carlin & $1992 / 94$ & Pennsylvania & 367 & $90,0 \%$ \\
\hline Judge & $1989 / 90$ & Ohio & 125 & $100 \%$ \\
\hline Hamlin & $1993 / 94$ & Illinois & 47 & $94,0 \%$ \\
\hline Hart & $1993 / 94$ & Indiana & 350 & $97,0 \%$ \\
\hline Carpenter e Parco & $1992 / 94$ & Nevada & 347 & $86,5 \%$ \\
\hline Carruthers & $1993 / 94$ & Carolina do Norte & 841 & $92,7 \%$ \\
\hline Crary & 1989 & California & 96 & $97,0 \%$ \\
\hline Kmitta e Berlowitz & $1993 / 95$ & Ohio & 248 & $82,2 \%$ \\
\hline Totais & & & 2.803 & $88,5 \%$ \\
\hline
\end{tabular}




\section{Algumas questões norteadoras para $o$ modelo de programa de mediação escolar}

Todo programa que se proponha a envolver grande número de variáveis, como é - caso das escolas, deve ter o cuidado de trabalhar a partir de generalizações. O Programa deve comportar-se tal qual um grande e delicado tecido jogado sobre um conjunto de peças com contornos distintos. $O$ tecido é o mesmo, mas ao alcançar a peça, toma a forma desta! Ele se amolda a cada realidade. Com um programa de mediação de conflito escolar não será diferente.

Nossa pretensão, ao apresentar um conjunto de distintas classificações de conflito foi permitir alternativas para identificação particularizada de cada contexto escolar. Não há receita na mediação de conflito que possa ser aplicada indistintamente a escolas diferentes. Cada escola é uma rede complexa de relações e de valores e, por tal, merecerá um diagnóstico específico de conflitos e um modelo próprio.

Temos algumas questões que representam eixos padrões de decisão que devem ser atendidos, ou não, no momento em que a escola debate a instalação de um programa de mediação.

Identificado o tipo de conflito que existe em cada escola, a partir das inúmeras classificações apresentadas anteriormente, a equipe disposta a implantar o programa de mediação de conflito escolar deverá responder a uma série de itens que definirão o tipo de programa que irão implantar. Escolhemos dez itens para este exercício de provo- cação e reflexão, em grande parte adaptados daqueles apresentados por Schvarstein (1998) e Chrispino e Chrispino (2002):

1. Caráter da Mediação de Conflito: obrigatório ou voluntário?

2. Alcance da Mediação de Conflito: Todos os conflitos ou apenas alguns conflitos?

3. Ênfase da Mediação de Conflito: No produto ou no processo?

4. Atores da Mediação de Conflito: todos os membros do universo escolar ou alguns membros do universo escolar?

5. Limites da Mediação de Conflito na Escola: sem limites de série, idade, turno, etc, ou com limites?

6. Relação da Mediação de Conflito com as Regras Disciplinares: sem relação ou com relação?

7. Relação da Mediação de Conflito com a Avaliação: sem relação ou com relação?

8. Identificação dos Mediadores de Conflito: mediação por pares ou outros mediadores?

9. Escolha dos Mediadores de Conflito: ação institucional ov escolha das partes?

10. Critérios para a Seleção dos Mediadores de Conflito: desempenho acadêmico ou "respeitabilidade" entre os pares?

\section{À guisa de conclusão}

Enquanto refletimos sobre a validade ou não de um programa de mediação de conflito, somos visitados por alguns pensamentos que estão no imaginário educacional, tais como: não foi para isso que estudei e me formei! Não foi para cuidar de problemas de aluno que fiz concurso público! Não sou pago para este tipo de trabalho! Isso é trabalho de orientador educacional! Estou perto de me aposentar! 
Não é nossa a proposta de contrapormo-nos a partir de cada uma dessas expressões. No exercício de controvérsia que pregamos ao longo deste trabalho, vamos, mais uma vez, apresentar grandes idéias que contemplam o "outro lado" e deixar que cada um reflita e decida. Afinal, podemos pensar diferentemente e isso faz parte das relações humanas. Vejamos o que nos diz Porro (2004):

\begin{tabular}{|l|}
\hline 7 GRANDES MOTIVOS PARA REALIZAR O PROGRAMA DE MEDIAÇÃO: \\
\hline 1. a capacitação em resolver conflitos valoriza o tempo; \\
\hline 2. a capacitação em resolver conflitos ensina várias estratégias úteis; \\
\hline 3. a capacitação em resolver conflitos ensina aos alunos consideração e respeito para com os demais; \\
\hline 4. a capacitação em resolver conflitos reduz o estresse; \\
\hline 5. possibilidade de aplicar as novas técnicas em casa, com familiares e amigos; \\
\hline 6. a capacitação em resolver conflitos que podem contribuir para a prevenção do uso do álcool e de drogas; \\
\hline 7. possibilidade de sentir a satisfação de estar contribuindo com a paz do mundo. \\
\hline
\end{tabular}

\section{Referências}

ABRAMOVAY, M.; RUA, M. G. Violências nas escolas. Brasília, DF: UNESCO, 2002.

CARREIRA, D. B. X. Violência nas escolas: qual o papel da gestão?. 2005. Dissertação (Mestrado em Educação)-Universidade Católica de Brasília, Brasília, DF, 2005.

CHRISPINO, A. Mediação de conflitos: cabe à escola tornar-se competente para promover transformações. Revista do Professor, Porto Alegre, ano 20, n. 79, p. 45-48, jul./set. 2004.

CHRISPINO, A.; CHRISPINO, R. S. P. Políticas educacionais de redução da violência: mediação do conflito escolar. São Paulo: Editora Biruta, 2002.

DEBARBIEUX, E.; BLAYA, C. (Org.). Violência nas escolas: dez abordagens européias. Brasília, DF: UNESCO, 2002.

FERNANDES, K. T. O conceito de violência escolar na perspectiva dos discentes. 2006. Dissertação (Mestrado em Educação)-Universidade Católica de Brasília, Brasília, DF, 2006.

HEREDIA, R. A. S. Resolución de conflictos en la escuela. Ensayos y Experiencias, Buenos Aires, ano 4, n. 24, p. 44-65, jul./ago. 1998.

JOHNSON, D. W.; JOHNSON, R. T. Como reducir la violencia en las escuelas. Buenos Aires: Paidós, 2004. 
KMITTA, D. Pasado y futuro de la evaluación e los programas de resolución de conflitos escolares. In: BRADONI, F. (Comp.). Mediación escolar. Buenos Aires: Paidos, 1999.

MARTINEZ ZAMPA, D. Mediación educativa y resolucion de conflictos: modelos de implementacion. Buenos Aires: Edicones Novedades Educativas, 2005.

MOORE, C. W. O processo de mediação: estratégias práticas para a resolução de conflitos. Porto Alegre: ARTMED, 1998.

NEBOT, J. R. Violencia y conflicto en los ámbitos educativos. Ensayos y Experiencias, Buenos Aires, ano7, n. 35, p.77-85, sept./oct. 2000.

OLIVEIRA, M. G. P. Percepção de valores nas escolas pelos docentes de ensino médio. 2003. Dissertação (Mestrado em Educação)-Universidade Católica de Brasília, Brasília, DF, 2003.

OLIVEIRA, M. G. P.; GOMES, C. A. Como os docentes vêem valores e violências escolares no ensino médio. RBPAE, Rio de Janeiro, v. 20, n. 1, p. 45-70, jan./jun. 2004.

OLIVEIRA, R. B. L. Significações de violências na perspectiva de professores que trabalham em escolas "violentas". 2004. Dissertação (Mestrado em Educação)Universidade Católica de Brasília, Brasília, DF, 2004.

ORTEGA, R.; DEL REY, R. Estratégias educativas para a prevenção da violência. Brasília, DF: UNESCO: UCB, 2002.

PORRO, B. La resolución de conflictos en el aula. Buenos Aires: Paidós, 2004.

REDORTA, J. Cómo analizar los conflictos: la tipologia de conflictos como herramienta de mediación. Barcelona: Edicones Paidós Ibérica, 2004.

RIBEIRO, R. M. C. Significações da violência escolar na perspectiva dos alunos. 2004. Dissertação (Mestrado em Educação)-Universidade Católica de Brasília, Brasília, DF, 2004.

RIO DE JANEIRO (RJ). O jovem, a sociedade e a ética. Rio de Janeiro: IBOPE., 2006. Disponível em: < http://oglobo.globo.com/rio/jovens.ppt >. Acesso em: 9 abr. 2007.

SCHVARSTEIN, L. Diseño de un programa de mediación escolar. Ensayos y Experiencias, Buenos Aires, ano 4, n. 24, p. 20-35, jul./ago. 1998. 
SILVA, M. N. Escola e comunidade juntas contra a violência escolar: diagnóstico e esboço de plano de intervenção. 2004. Dissertação (Mestrado em Educação)-

Universidade Católica de Brasília, Brasília, DF, 2004.

VALE, C. M. R. Violência simbólica e rendimento escolar. 2004. Dissertação (Mestrado em Educação)-Universidade Católica de Brasília, Brasília, DF, 2004.

Recebido em: 31/10/2006

Aceito para publicação em: 5/02/2007 